\title{
Reimagining Energy: Deconstructing Traditional Engineering Silos Using Culturally Sustaining Pedagogies
}

\section{Dr. Gordon D. Hoople, University of San Diego}

Dr. Gordon D. Hoople is an assistant professor of general engineering at the University of San Diego. His research interests lie in microfluidics, rapid prototyping, genomics, engineering ethics, and engineering education. He earned his MS and $\mathrm{PhD}$ in mechanical engineering from University of California, Berkeley and a BS in engineering from Harvey Mudd College.

\section{Dr. Joel Alejandro Mejia, University of San Diego}

Dr. Joel Alejandro (Alex) Mejia is an assistant professor of General Engineering at the University of San Diego. His current research investigates the funds of knowledge of Latinx adolescents, and how they use these funds of knowledge to solve engineering problems in their communities. Dr. Mejia is particularly interested in how Latinx adolescents bring forth unique ways of knowing, doing, and being that provide them with particular ways of framing, approaching, and solving engineering problems. He is also interested in engineering critical literacies, equity-oriented instructional strategies that support engineering activity, the use and application of critical theories in engineering education, and the development of critical consciousness among engineering students through social justice.

\section{Dr. Diana A. Chen, University of San Diego}

Dr. Diana A. Chen is an Assistant Professor of General Engineering at the University of San Diego. She joined the Shiley-Marcos School of Engineering in 2016. Her research interests are in areas of sustainable design, including biomimicry and adaptability in structural, city, and regional applications. She earned her MS and PhD in Civil Engineering from Clemson University in South Carolina, and her BS in Engineering from Harvey Mudd College.

\section{Dr. Susan M. Lord, University of San Diego}

Susan M. Lord received a B.S. from Cornell University and the M.S. and Ph.D. from Stanford University. She is currently Professor and Chair of Electrical Engineering at the University of San Diego. Her teaching and research interests include electronics, optoelectronics, materials science, first year engineering courses, feminist and liberative pedagogies, engineering student persistence, and student autonomy. Her research has been sponsored by the National Science Foundation (NSF). Dr. Lord is a fellow of the ASEE and IEEE and is active in the engineering education community including serving as General Co-Chair of the 2006 Frontiers in Education (FIE) Conference, on the FIE Steering Committee, and as President of the IEEE Education Society for 2009-2010. She is an Associate Editor of the IEEE Transactions on Education. She and her coauthors were awarded the 2011 Wickenden Award for the best paper in the Journal of Engineering Education and the 2011 Best Paper Award for the IEEE Transactions on Education. In Spring 2012, Dr. Lord spent a sabbatical at Southeast University in Nanjing, China. 


\title{
Reimagining Energy: Deconstructing Traditional Engineering Silos using Culturally Sustaining Pedagogies
}

\begin{abstract}
$\underline{\text { Abstract }}$
Energy is a foundational topic across engineering disciplines; however, energy concepts are typically introduced in a disjointed fashion across multiple courses. Students often have difficulty making connections across disciplines that leverage their own personal funds of knowledge. For example, many students often fail to connect their personal experience with technology (e.g. home appliances) with the engineering concepts (e.g. 1st law of thermodynamics) introduced in class. We are exploring a reconceived approach for introducing students to these important concepts. The authors, with expertise in four different engineering disciplines, recognize that many discourses in engineering exist in tension with each other. The context in which we teach energy is too often narrowly defined and framed by both hegemonic disciplinary literacies (i.e., mechanical engineers tend to focus heavily on steam tables) and dominant cultural perspectives (i.e., White, male, colonial, and heteronormative). Our objective is to redefine the teaching and learning of energy in engineering to recognize the broad diversity that exists within the world around energy. This paper, submitted as a work in progress, describes our vision for a new course that brings together energy concepts from traditional middle year courses such as thermodynamics and circuits. We propose to use culturally sustaining pedagogies (CSPs) to provide all students with a stronger foundation and a broader perspective. CSPs seek to value and cultivate the cultural and social pluralism that creates a democratic educational experience and have been shown to increase student engagement and improve student outcomes in K-12 education. We hypothesize that the use of CSPs will help with breaking down the false dichotomy of engineering problems as strictly "social" or "technical." In this paper, we briefly review approaches taken to teach energy in engineering. We then examine CSPs and make the case for how they might be used within engineering. We discuss our preliminary ideas for the course itself. The goal of this paper is to stimulate discussion within the ASEE community to improve course effectiveness in enhancing student learning. This project is part of a larger overall effort at the University of San Diego to integrate social justice themes across the curriculum of a new general engineering department. This paper will present our progress towards instantiating in the classroom the broader vision laid out for our program.
\end{abstract}




\section{Introduction}

There is an unquestioned assumption that certain ways of knowing -- explicitly dominant epistemologies that involve specific mathematical procedures and scientific processes -- are race-, gender-, and culture-free. In reality, education inherently prioritizes and privileges certain bodies of knowledge while marginalizing and excluding others. Within engineering, colonial, White, heterosexual, and male knowledge has historically been privileged over other ways of knowing. Little recognition appears to exist that the ethnocentricity and masculinity of the engineering curricula affects problem definition and accepted methods of problem solving, teaching, and assessment [1]. This dominant approach undervalues and ignores the lived realities, perspectives, and epistemologies of those students who do not fit into this dominant category.

One approach that has been shown to disrupt this dominant discourse is the use of culturallysustaining pedagogies (CSPs) [2]-[6]. CSPs seek to value and cultivate the cultural and social pluralism that creates a democratic educational experience and have been shown to increase student engagement and improve student outcomes in K-12 education. CSPs (and related approaches, including culturally relevant pedagogy (CRP)) have emerged in recent years as pedagogical approaches that focus on enhancing inclusivity - yielding positive results with women and retention of underrepresented minorities in K-12 education [7]-[9], improving mathematics [10] and computer science achievement [11], and developing science communication [12]. For instance, Grimberg and Gummer analyzed how science test scores increased after teachers adopted CSPs into their curriculum. The study described students' achievement gains in science as they made "connections between science and topics relevant to their life and community" [9].

Although there have been great strides in improving achievement in science and mathematics through CSP methods, the incorporation of CSP into engineering has not been explicitly explored in higher education. There is a need for engineering educators to continue to implement and adopt new pedagogies that position engineering graduates to be responsive to the needs of an increasingly complex and diverse society.

At the University of San Diego, we are committed to broadening the definition of engineering. Instead of perpetuating a false division between technical and social aspects of problems, we seek to explicitly recognize engineering as a socio-technical discipline. As Erin Cech writes, "Prioritizing certain 'technical' features (faster, smaller, cheaper vs. quality or sustainability) over others is a social and political choice at its core. Thus, the notion that engineering work can somehow be separated from the social world is itself a cultural frame for understanding what engineering is [13]." We envision an innovative engineering culture that is inherently interdisciplinary, engaging faculty across engineering departments and across campus to provide students with an engineering education that is explicitly socio-technical in nature.

We plan to develop a transformative, inclusive approach to teaching energy as a model for how to adopt culturally-sustaining pedagogies within engineering. We have selected energy, as it is a foundational topic across multiple engineering disciplines, relevant to students' lived 
experiences, and has important social ramifications. We are targeting a class in the second year to provide students with a grounding in CSP early in their engineering education so that they might use these mindsets moving forward. Many students often first see energy concepts in "Introduction to Thermodynamics." With its grounding in 18th century power cycles and steam engines, this class often epitomizes the colonial, White, and male frameworks that can be so problematic. We aim to take the example set by Riley with her companion textbook Engineering Thermodynamics and 21st Century Energy Problems [14] to the next level by designing a course from the ground up to include the social and technical in an integrated student experience.

\section{What is Energy and how is it taught?}

The word "energy" brings with it a series of broad associations that vary greatly based on audience. The Oxford English Dictionary first defines energy as "force or vigour of expression [15]." Only at the sixth definition of the word is the scientific connotation of the word introduced:

The power of 'doing work' possessed at any instant by a body or system of bodies. First used by Young... to denote what is now called actual, kinetic, or motive energy, i.e. the power of doing work possessed by a moving body by virtue of its motion. (Young expressed the quantity of 'energy' in a particle as the product of the mass into the square of the velocity; it is now found more convenient to express it as the half of this product.) Now extended (first by Rankine) to include potential, static, or latent energy, or energy of position, i.e. the power of doing work possessed by a body in virtue of the stresses which result from its position relatively to other bodies. Also with [adjectives], mechanical energy, molecular energy, chemical energy, electrical energy, etc.;

This definition nicely captures the complexity of the term. Usage of the word "energy" began in the 1800s during the industrial revolution, however as time passed more and more concepts found a home under the broad category of energy. Today, energy is found across the sciences and engineering to cover concepts ranging from nuclear fission to protein folding. In this section, we briefly review several approaches engineering educators take to teaching energy. This section is not meant to be an exhaustive review, but instead provides some context in which to situate our proposed energy course. The authors, each from a different engineering discipline, report briefly on how energy is taught within their field. This is followed by a brief review of some existing approaches for teaching energy in an interdisciplinary fashion.

\section{Engineering Approaches to Teaching Energy}

Within Mechanical Engineering, students typically first see energy concepts in thermodynamics in their second year of engineering study- a course taught by author $\mathrm{GH}$. This course is heavily influenced by discoveries and examples from the Industrial Revolution. Students learn to read steam tables as they develop an understanding of steam engines and power cycles. Energy is divided into two categories - heat and work - and the course examines how useful work can be 
derived from heat gradients. Emphasis is placed on the fundamental laws of thermodynamics the 0th Law (temperature), first law (conservation of energy), and the second law (entropy). It has been documented that students come to a thermodynamics course with the expectation of being exposed to real world content but traditional textbook and course format have not been able to meet those expectations [16]. Most introductory texts reserve topics of renewable energies as a final bonus chapter [17], [18].

Within Electrical Engineering, where author SL teaches, energy topics are introduced in the introductory circuits course in the second year. The focus is typically on "power", energy per unit time, rather than energy. Concepts such as conservation of power and maximum power transfer are important. Sinusoidal steady-state and three-phase power calculations are typically covered in the end of the first circuits course [19]. The application or context for these topics is usually household power distribution with an underlying assumption of a fossil fuel powered plant as the source. Topics relating to renewable energy such as light emitting diodes or solar power are usually found in upper division elective courses.

Materials scientists, author JM's disciplinary background, use concepts of energy to primarily teach how reactions behave in materials. These courses include the description, characterization, and prediction of the properties and behaviors of materials [20]. Students are introduced to different principles used to understand equilibrium, phase diagrams, solutions, heterogeneous reactions, interfaces, and entropy and enthalpy among others. These concepts are sometimes too intangible for students, and very little context is provided that relates those concepts to everyday life experiences [21].

Within Civil Engineering, author DC's disciplinary background, the human consumption of energy is addressed more so than the concept of energy itself, and often only in curricula that have an explicit focus on sustainability. Sustainability courses are seen at any level in the undergraduate curriculum, but many traditional programs leave these as upper-level electives or graduate courses. Topics covered often include civil infrastructure's greenhouse gas footprint, life cycle analyses and embodied energy of construction materials, environmentally-informed design of transportation and building systems, energy efficiency (e.g., LEED ratings), and the business case for sustainability through energy cost savings [22]. As civil infrastructure has one of the slowest rates of change within science and engineering disciplines, educational progress in sustainability -- and by proxy, energy -- appears to still be in its initial stages of establishing legitimacy in a long-established discipline.

\section{Interdisciplinary Approaches to Teaching Energy}

While energy concepts are typically taught using siloed approaches, there have been attempts to take a more interdisciplinary approach. Several universities, including Penn State [23], Indiana University - Purdue University Indianapolis [24], and UC Berkeley [25], offer a B.S. in Energy Engineering. While these programs do expose students to energy concepts from across the curriculum, they usually require students to take standard foundational courses such as thermodynamics and circuits. It is not until the third or fourth year that they introduce courses to synthesize information across disciplines. 
At the course level, several faculty members have developed textbooks that take a more interdisciplinary approach. We have found physicists Hinrichs and Kleinbach's Energy: Its Use and the Environment to be a particularly useful reference [26]. This text introduces students to energy in the context of the environment and begins with foundational concepts relating to energy mechanics, heat and work, and conservation of energy. This foundation is used to explore more complex topics of home energy conservation, solar energy, and fossil fuel power plants. While this text (and others) succeed in deconstructing disciplinary silos, they do not attempt to deconstruct the dominant cultural perspectives. By combining an interdisciplinary approach with CSP methods, we hope to deconstruct a broad range of engineering silos.

\section{Using CSP to Deconstruct Silos}

One of the challenges we see with engineering education is that it reinforces a variety of silos in students' learning. One of the most obvious examples is the use of disciplinary silos as a crutch to avoid engaging in unfamiliar material. For example, this past fall a group of senior mechanical engineering students at our institution faced with making a basic electrical measurement declared "I don't know how to do that, I'm not an electrical engineer," even though Circuits is a required second year course for all of our engineering students. Disciplinary silos are problematic, but there are several interdisciplinary models to teaching energy we can employ to help break down these silos [23]-[26].

Unfortunately we see an even more problematic set of silos: the division between society, lived experiences, and engineering. Engineering (broadly), as mentioned above, is traditionally taught as a purely technical discipline. Given a narrowly defined problem, there are a set of "rigorous" equations that can be used to create a model of reality that in turn can be used to identify a solution. Engineering educators tend to treat "society" as a distinctly separate silo from engineering itself. This is not to say that society isn't discussed within the engineering classroom, but it is often framed as a linear progression -- something is engineered, then it has an impact on society. This is reflected in the 2016-2017 ABET outcome $\mathrm{H}$ : "the broad education necessary to understand the impact of engineering solutions in a global, economic, environmental, and societal context." The very language of this statement indicates societal context is seen as relevant, but distinctly separate, from engineering solutions.

Similarly, students' lived experiences are typically contained in a separate silo. Students bring with them to university a rich diversity of experiences that may have piqued their interest in engineering. This lived experience, however, is rarely recognized within the classroom. In a longitudinal study of why students choose engineering, Matusovich, Streveler, and Miller conclude "to increase persistence rates we must focus on values, especially by helping students connect their personal identities to engineering identities [27]." They conclude that the divide between students' personal identities (in our language, "lived experiences") and what is recognized as engineering is a major factor in discouraging students from continuing in engineering programs. 


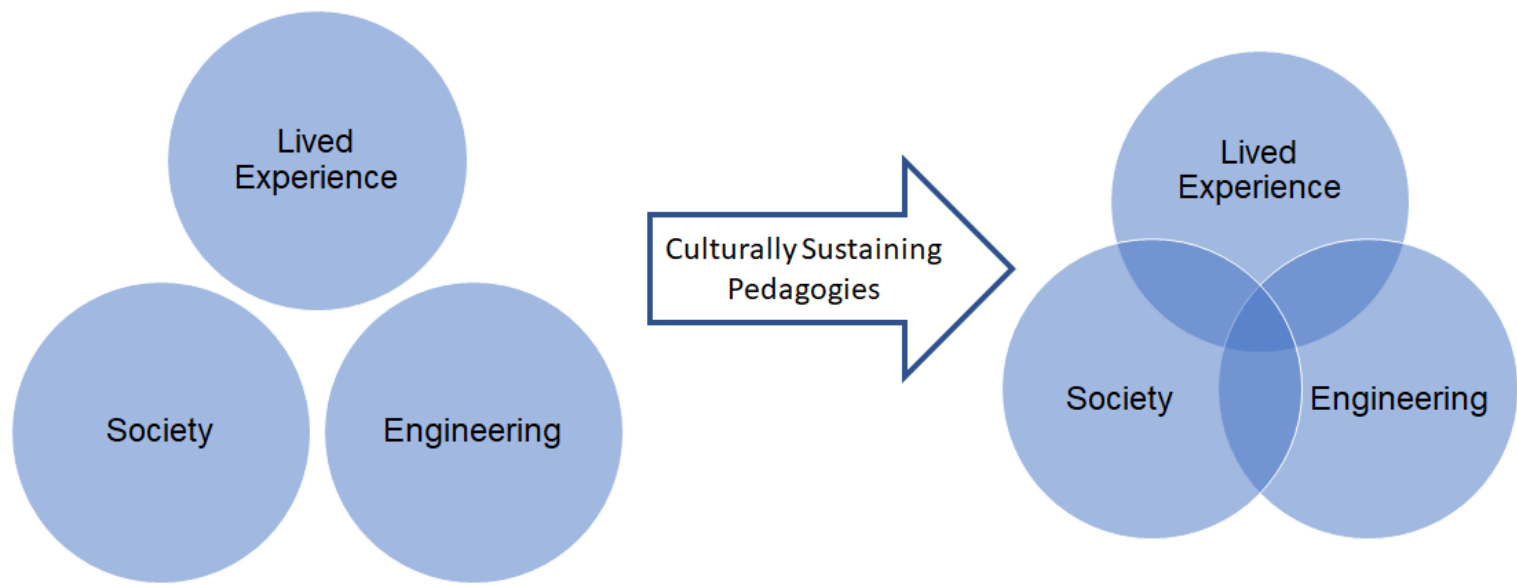

Figure 1. Engineering education tends to create silos between students' lived experiences, society, and engineering itself. We see culturally sustaining pedagogies (CSPs) as a curricular approach that helps students see the interplay between these three areas.

We hypothesize that CSPs can help move engineering education away from a pedagogy that reinforces separation between lived experience, society, and engineering and towards one that brings the three together (Figure 1). We believe CSPs can have substantial benefits across the curriculum and will help educators to achieve the recently released 2019-2020 ABET outcomes. We hypothesize CSPs will help students to:

- make clear connections between engineering, science, and math concepts learned in class with real world engineering problems (Aligning with ABET Outcome 1)

- apply engineering design to create solutions that consider the global, cultural, social, and environmental factors (Aligning with ABET Outcome 2)

- communicate across disciplinary boundaries using appropriate language (Aligning with ABET Outcome 3)

- describe engineering as a socio-technical discipline and recognize the implications this has on the ethical and professional responsibility of engineers (Aligning with ABET Outcome 4)

\section{What are culturally sustaining pedagogies?}

Culturally sustaining pedagogies (CSPs) is a term that represents a compilation of studentcentered approaches to teaching with the intent of connecting the life experiences of students with classroom instruction. CSPs seek to perpetuate and foster (or sustain) the linguistic, literate, and cultural pluralism that is necessary for transformation of schooling [28]. According to Paris (2012), CSPs exist wherever it sustains the everyday life experiences, lifeways, and embodied knowledge of the communities that have been and continue to be damaged and erased from formal education spaces. Thus, CSPs seek to "sustain" -- rather than eradicate -the cultural ways of thinking, doing and being of communities of color [28]. CSPs are grounded in the following tenets from culturally relevant education [29] which include the ability to:

1. create an environment where students are provided with the tools to achieve academic success, 
2. foster cultural competence, and

3. develop a socio-political and critical consciousness in students.

CSPs enhance faculty-student relationships with structured exchanging of ideas [28]. CSPs rely on students bringing into the classroom their bodies of knowledge, skills, and practices while the instructor emphasizes, validates, acknowledges, and incorporates such wealth of knowledge to the curriculum. A rejection by an instructor of an individual student's own ways of knowing and doing can form a 'virtual barrier' by which students may feel excluded from gaining entry into the engineering discipline [30]. CSP as a framework encourages instructors to facilitate students sharing and connecting their experiences with technical content in the classroom [28]. Quite simply, an instructor prompting students for real-world examples in lecture can sufficiently validate students' self-efficacy [29], [31], [32]. This validation not only engages students and promotes the retention of students, but it also enhances the quality of education as the instructor gains insights into their students [33].

As an example where CSPs were used for a science lesson on the different parts of a plant, students were asked to gather information from their families and share their favorite home salads [34]. This activity allowed students to actively participate in class, share something they were familiar with, and contribute to the classroom science discourse. Home interactions, such as learning from parents about healthy foods, created a sense of nutritional awareness developed through home funds of knowledge and learning from those experiences. Discussing the home salad recipes with family members provided students with the rationale to engage in scientific discourse in the classroom regarding the good nutritional value of salads [34]. Barton and Tan argued that this instructional approach "fostered new opportunities to engage the subject matter that promoted both academic achievement and inclusion" [34]. It is through these types of teacher and student interactions that culturally sustaining pedagogies become possible in the science classroom.

CSP builds on research dedicated to emphasize asset-based approaches to education that counter the deficit models that have persisted in education [35]-[37]. CSP includes work on funds of knowledge [38], hybrid spaces [39], culturally responsive pedagogy [40], and culturally relevant pedagogy [29]. The CSP model recognizes that students bring a wealth of knowledge to the classroom and focuses on the learning strengths of the students while fostering their linguistic, literate, and cultural practices [28]. CSPs also build on other strategies to address the needs of changing and dynamic systems [29]. This is in keeping with recent work in engineering education which adopts an asset-based rather than deficit-based approach to research on underrepresented populations.

\section{How can CSP be used in engineering?}

While there is some research on teaching engineering in $\mathrm{K}-12$ settings using CSP [41]-[47], and there are a few examples of CSP in higher education focusing on teacher preparation [6], [48], [49], there is little work on implementing these strategies with college students. One exception is Miller's investigation of the impact of culturally-responsive teaching on retention of women and men of color in introductory computer science classes [50]. In part, there exist misconceptions 
regarding what CSPs are, a lack of research connecting its effectiveness to engineering student achievement, and a fear of loss of influence of majority-male norms and practices [51]. In the face of an evolving demographic in engineering education, where cultural and social needs are sometimes overlooked [52], a different approach must be used to adapt to these new changes. CSPs tap into the idea that the engineering way of knowing, doing, and being [1] involve epistemologies that emerge from social and cultural practices in people's everyday lives and are used under different contexts and domains. CSPs also challenge the conflicted view of what counts as engineering knowledge and what kind of knowledge is valued. In a study of engineering culture, Godfrey and Parker indicated that "no recognition appeared to exist that the ethnocentricity and masculinity of engineering knowledge and procedures might affect problem definition and accepted methods of problem solution, teaching, and assessment" [1]. Thus, CSPs create a hybrid space where students develop and construct an engineering identity that acknowledges long-neglected epistemologies.

Although CSPs have typically been used to support traditionally marginalized students, we assert that CSPs can be beneficial for all students. CSP's encouragement of all students to share their ideas helps individuals acknowledge the differing values and perspectives that others hold. Thus, CSP helps connect all students' lived experience to engineering education. In engineering in particular, given the lack of diversity of the student population, CSP offer a valuable tool for enhancing student learning. For example, if the instructor introduces examples from non-dominant cultures or paradigms, this emphasizes that engineering knowledge comes from many sources expanding the definition of what "counts" as engineering and who is involved in the endeavor. This helps all engineering students to develop their abilities to function as culturally competent and engaged engineering professionals who are better equipped to navigate socio-scientific and socio-political challenges in the workforce. Thus we believe that this use of CSP in a traditional engineering classroom connects students' lived experiences to engineering education and to society (see Figure 1). As Paris and Alim pointed out, CSP highlights the evolving nature of youth identity while allowing them to maintain "a clear-eyed critique of the ways in which youth culture can also reproduce systemic inequalities" [53].

\section{Our Course Vision}

To successfully develop a reimagined energy course, our first task is to identify non-canonical energy examples that can be used as a CSP approach for teaching engineering. Our goal is to identify examples that are explicitly not colonial, White, heterosexual, and male. We have already identified one such example: the Lorena stove. The following vignette is used to describe how examples of collective knowledge that are grounded in historical, cultural, and linguistic experiences learned by practice and/or observation can be used to situate engineering in different sociocultural contexts. This vignette was developed from dissertation work of JM related to funds of knowledge [54] to highlight the embodied knowledge of groups that remain on the margins of society, and how this wealth of knowledge relates to engineering practices, habits of mind and dispositions [35]. 
Laura did not have the resources to buy a new stove. Her family owned a restaurant in Mexico and they needed the stove as soon as possible. To solve this problem, Laura and her family designed a stove made out of inexpensive raw materials, including adobe, empty coffee and soup cans, barro (a mixture of clay materials), and a pipe. They also repurposed an antique washing machine, called chaca-chaca (as it is commonly known in Mexico for the sound it makes during the washing cycle), by disassembling it and using the tub as the skeleton for the fuel chamber. They placed the steel tub of the chaca-chaca and the biggest empty soup can in a wooden form and filled the form with barro. The steel tub served as the fuel chamber while the empty soup cans served as the heat chamber. As they were filling up the form with barro, they made sure to connect the different chambers created with smaller empty soup cans, which eventually became the chimney pipe. They carefully added adobe around the bucket, cans, and pipes to prevent collapse. Laura knew that excessive amounts of barro caused the stove to crack when heated, so she made sure to add just enough barro to prevent collapse but also maintain high temperatures to cook the food.

We propose to develop a project-based learning module around this vignette where students must design and build their own Lorena stoves. This module can provide students ample exploration of topics related to insulation, thermal mass, conduction, convection, and efficiency when heating under specific constraints and within cultural, social, and historical contexts. It also exposes students to an inventive method used for many years by indigenous communities to heat their homes.

To create a truly transformative course, we anticipate needing 2-3 additional examples to the Lorena stove. While we have not yet fully defined the criteria for these examples, they will need to be topically relevant to the technical subject matter, culturally relevant to multiple stakeholders, and originate from outside the engineering canon. To develop such examples, we plan to speak with experts outside of traditional engineering circles as well as conduct our own field research. One area of interest is Native Science, a field pioneered by Cajete. He defines Native Science as a "wide range of tribal processes of perceiving, thinking, acting, and 'coming to know' that have evolved through human experience with the natural world [55]."

Once we have identified these examples, we will then use them to develop an energy course based in culturally sustaining pedagogies. Targeted at second year engineering students, this will be a required course for all students in General Engineering and open to students across the School of Engineering. Rather than teaching a slightly revised version of Circuits or Thermodynamics, we envision a complete redesign of the course. Our approach will provide a modern look at energy and emphasize concepts relevant to students regardless of their eventual career path. Our development will be guided by the question "What does the engineer of 2040 need to understand about energy?" Following best pedagogical practices, we will start by identifying learning objectives for the course. Our current draft of learning objectives includes the following:

Students should be able to: 
1. Solve engineering problems using energy concepts (e.g. heat, work, conservation of energy)

2. Discuss energy using multiple engineering disciplinary discourses (e.g., ME, EE)

3. Provide and explain how two examples of energy concepts discussed in this course relate to their everyday life

4. Describe to a peer what it means for engineering to be a socio-technical profession

In developing a schedule and specific lessons around these objectives, we will focus on connecting engineering, lived experiences, and societal context (see Figure 1). We hope that integrating CSP into our course development will help students grasp the complexity of engineering practice. We plan to co-develop the materials during multiple daylong workshop sessions rather than taking a divide and conquer approach. In this way we will take advantage of the interdisciplinary experience of the authors and avoid creating silos within different sections of the course.

\section{Future Work}

We argue that CSPs are a promising area for enhancing engineering education and we look forward to investigating these methods. Future work will focus on identifying appropriate examples for teaching energy concepts through CSP, developing and offering the course, and measuring the impact of CSP on student learning. One of our major challenges will be determining how the examples identified in this research can best be integrated to achieve our desired learning outcomes. We anticipate that we will need to overcome our own biases about what counts as engineering and that by working as a group we can collectively broaden our own definitions of engineering. 


\section{References}

[1] E. Godfrey and L. Parker, "Mapping the Cultural Landscape in Engineering Education," J. Eng. Educ., vol. 99, pp. 5-22, 2010.

[2] T. McCarty and T. S. Lee, "Critical culturally sustaining/revitalizing pedagogy and Indigenous educational sovereignty," Harvard Educ. Rev., vol. 84, no. 1, pp. 101-124, 2014.

[3] H. S. Alim, "Critical Hip-Hop Language Pedagogies: Combat, Consciousness, and the Cultural Politics of Communication," J. Lang. Identity Educ., vol. 6, no. 2, pp. 161-176, 2007.

[4] J. Irizarry, The Latinization of U.S. Schools: Successful Teaching and Learning in Shifting Cultural Contexts. Routledge, 2015.

[5] V. Kinloch, Harlem on Our Minds: Place, Race, and the Literacies of Urban Youth. Language \& Literacy Series. Teachers College Press, 2009.

[6] D. Paris and H. S. Alim, Culturally sustaining pedagogies: Teaching and learning for social justice in a changing world. Teachers College Press, 2017.

[7] K. A. Morrison, H. H. Robbins, and D. G. Rose, "Operationalizing Culturally Relevant Pedagogy: A Synthesis of Classroom-Based Research," Equity Excell. Educ., vol. 41, no. 4, pp. 433-452, Oct. 2008.

[8] C. C. Johnson, "The road to culturally relevant science: Exploring how teachers navigate change in pedagogy," J. Res. Sci. Teach., vol. 48, no. 2, pp. 170-198, Feb. 2011.

[9] B. I. Grimberg and E. Gummer, "Teaching science from cultural points of intersection," J. Res. Sci. Teach., vol. 50, no. 1, pp. 12-32, Jan. 2013.

[10] W. F. Tate, "Returning to the root: A culturally relevant approach to mathematics pedagogy," Theory Pract., vol. 34, no. 3, pp. 166-173, Jun. 1995.

[11] T. Yuen, M. Arreguín-Anderson, G. Carmona, and M. Gibson, "A culturally relevant pedagogical approach to computer science education to increase participation of underrepresented populations," in Proceedings - 2016 International Conference on Learning and Teaching in Computing and Engineering, LaTiCE 2016, 2016, pp. 147-153.

[12] J. D. Lemus, K. D. Seraphin, A. Coopersmith, and C. K. V. Correa, "Infusing Traditional Knowledge and Ways of Knowing Into Science Communication Courses at the University of Hawai'i,"” J. Geosci. Educ., vol. 62, no. 1, pp. 5-10, Feb. 2014.

[13] E. A. Cech, "the (mis)framing of social justice: Why ideologies of depoliticization and meritocracy hinder engineers' ability to think about social injustices," in Engineering Education for Social Justice: Critical Explorations and Opportunities, Springer, 2013, pp. 67-84.

[14] D. Riley, Engineering Thermodynamics and 21st Century Energy Problems: A Textbook Companion for Student Engagement. Morgan \& Claypool Publishers, 2011.

[15] energy, "OED Online," Oxford University Press, 2018.

[16] P. Tebbe and S. Ross, "Full Development Of Engineering Scenarios To Promote Student Engagement In Thermodynamics - Year 1," in ASEE Annual Conference Proceedings, 2010.

[17] M. J. Moran and H. N. Shapiro, Fundamentals of Engineering Thermodynamics. Wiley, 2014.

[18] Y. A. Cengel and M. A. Boles, An Engineering Approach. McGraw-Hill Education, 2015.

[19] J. W. Nilsson and S. A. Riedel, Electric circuits. Pearson, 2014.

[20] R. T. DeHoff, Thermodynamics in materials science. CRC Press, 2006.

[21] V. I. Ugursal and C. A. Cruickshank, "Student opinions and perceptions of undergraduate thermodynamics courses in engineering," Eur. J. Eng. Educ., vol. 40, no. 6, pp. 593-610, Nov. 2015.

[22] A. R. Pearce, Y. H. Ahn, and Hanmi Kŭllobŏl Chusik Hoesa., Sustainable buildings and infrastructure : paths to the future. Routledge, 2012.

[23] Penn State, "Energy Engineering." [Online]. Available: http://www.eme.psu.edu/eneng. [Accessed: 30-Jan-2018].

[24] IUPUI Purdue School of Engineering and Technology, "Overview-Mechanical and Energy Engineering." [Online]. Available: http://www.engr.iupui.edu/departments/me/undergrad/bseen/index.php. [Accessed: 30-Jan-2018].

[25] UC Berkeley, "Energy Engineering." [Online]. Available: http://guide.berkeley.edu/undergraduate/degree-programs/energy-engineering/. [Accessed: 30Jan-2018].

[26] R. Hinrichs and M. H. Kleinbach, Energy: its use and the environment. Brooks Cole, 2012.

[27] H. M. Matusovich, R. A. Streveler, and R. L. Miller, "Why Do Students Choose Engineering? A 
Qualitative, Longitudinal Investigation of Students' Motivational Values," J. Eng. Educ., vol. 99, no. 4, pp. 289-303, 2010.

[28] D. Paris, "Culturally Sustaining Pedagogy: A Needed Change in Stance, Terminology, and Practice," Educ. Res., vol. 41, no. 3, pp. 93-97, 2012.

[29] G. Ladson-Billings, "Culturally Relevant Pedagogy 2.0: a.k.a. the Remix," Harv. Educ. Rev., vol. 84, no. 1, pp. 74-84, Apr. 2014.

[30] J. A. Whittaker and B. L. Montgomery, "Cultivating Diversity and Competency in STEM: Challenges and Remedies for Removing Virtual Barriers to Constructing Diverse Higher Education Communities of Success.," J. Undergrad. Neurosci. Educ., vol. 11, no. 1, pp. A44-51, 2012.

[31] E. Young, "Challenges to Conceptualizing and Actualizing Culturally Relevant Pedagogy: How Viable Is the Theory in Classroom Practice?," J. Teach. Educ., vol. 61, no. 3, pp. 248-260, May 2010.

[32] S. A. Hofacker, "Diversity and Inclusion in the Engineering Workplace : A Call for Majority Intentionality to Increase Career Self-Efficacy," ASEE Southeast Sect. Conf., 2014.

[33] K. Samuelowicz and J. D. Bain, "Conceptions of teaching held by academic teachers," High. Educ., vol. 24, no. 1, pp. 93-111, Jul. 1992.

[34] A. C. Barton and E. Tan, "Funds of knowledge and discourses and hybrid space," J. Res. Sci. Teach., vol. 46, no. 1, pp. 50-73, Jan. 2009.

[35] A. Wilson-Lopez, J. A. Mejia, I. M. Hasbún, and G. S. Kasun, "Latina/o Adolescents' Funds of Knowledge Related to Engineering," J. Eng. Educ., vol. 105, no. 2, pp. 278-311, Apr. 2016.

[36] C. C. Samuelson and E. Litzler, "Community Cultural Wealth: An Assets-Based Approach to Persistence of Engineering Students of Color," J. Eng. Educ., vol. 105, no. 1, pp. 93-117, 2016.

[37] V. Svihla et al., "Designing for assets of diverse students enrolled in a freshman-level computer science for all course," in ASEE Annual Conference Proceedings, 2017.

[38] L. C. Moll, C. Amanti, D. Neff, and N. Gonzalez, "Funds of knowledge for teaching: Using a qualitative approach to connect homes and classrooms," Theory Pract., vol. 31, no. 2, pp. 132141, Mar. 1992.

[39] E. B. Moje, K. M. Ciechanowski, K. Kramer, L. Ellis, R. Carrillo, and T. Collazo, "Working toward third space in content area literacy: An examination of everyday funds of knowledge and Discourse," Read. Res. Q., vol. 39, no. 1, pp. 38-70, Jan. 2004.

[40] G. Geneva, Culturally responsive teaching: theory, research, and practice. Teachers College, 2000.

[41] S. Guzey, T. Moore, and G. Roehrig, "Bridge design on the reservation: A study of curriculum implementation with American Indian youth," in ASEE Annual Conference Proceedings, 2009.

[42] S. S. Jordan, "CAREER : Engineering Design Across Navajo Culture , Community , and Society," in ASEE Annual Conference Proceedings, 2014.

[43] S. S. Jordan et al., "Culturally-Relevant Engineering Design Curriculum for the Navajo Nation," in ASEE Annual Conference Proceedings, 2017.

[44] D. Bonuccelli, C., \& Davis, "Engaging K-12 Students In Engineering Design Of Cooling Systems For Electronics," in ASEE Annual Conference Proceedings, 2010.

[45] D. Newberry, "Modification of Nanoscience Educational Content to Reach a Greater Number of Educators," in ASEE Annual Conference Proceedings, 2015.

[46] A. Navickis-Brasch, S. Aimee, A. Kern, F. Fiedler, and J. Cadwell, "Restoring Water, Culture, and Relationships: Using a Community Based Participatory Research Methodology for Engineering Education," in ASEE Annual Conference Proceedings, 2014.

[47] A. S. Navickis-Brasch, A. L. Kern, J. R. Cadwell, L. Laumatia, and F. Fiedler, "How Land Use Changed Culture," in ASEE Annual Conference Proceedings, 2013.

[48] D. Paris, "On Educating Culturally Sustaining Teachers," Teaching Works, University of Michigan, 2016. [Online]. Available: http://www.teachingworks.org/images/files/TeachingWorks_Paris.pdf.

[49] T. E. Jester, "Preparing Culturally Sustaining/Revitalizing Educators: Lessons from Field Experiences in Alaska Native Village Schools," in Culturally Sustaining and Revitalizing Pedagogies: Language, Culture, and Power, Emerald Insight, 2017, pp. 127-146.

[50] O. Miller, "Gaining Insights into the Effects of Culturally Responsive Curriculum on Historically Underrepresented Students ' Desire for Computer Science," in ASEE Annual Conference Proceedings, 2016.

[51] C. E. Sleeter, "Confronting the Marginalization of Culturally Responsive Pedagogy," Urban Educ., 
vol. 47, no. 3, pp. 562-584, May 2012.

[52] D. M. Riley, "What's wrong with evidence? Epistemological roots and pedagogical implications of 'evidence-based practice' in STEM education," in ASEE Annual Conference Proceedings, 2014.

[53] D. Paris and H. S. Alim, "What Are We Seeking to Sustain Through Culturally Sustaining Pedagogy? A Loving Critique Forward," Harv. Educ. Rev., vol. 84, no. 1, pp. 85-100, 2014.

[54] J. A. Mejia, "A sociocultural analysis of Latino high school students' funds of knowledge and implications for culturally responsive engineering education (PhD Dissertation)," Utah State University, 2014.

[55] G. Cajete, Native science : natural laws of interdependence. Clear Light Publishers, 2000. 